\title{
Relationship between the dietary glycemic load of the adult Polish population and socio-demographic and lifestyle factors - results of the WOBASZ II study
}

\author{
Dorota Różańska ${ }^{1, A-E}$, Anna Waśkiewicz, ${ }^{2, A-C, E}$, Bożena Regulska-llow ${ }^{1, A-C, E}$, Magdalena Kwaśniewska 3,B,E, Andrzej Pająk k,B,E, \\ Urszula Stepaniak ${ }^{4, B, E}$, Krystyna Kozakiewicz ${ }^{5, B, E}$, Andrzej Tykarski ${ }^{6, B, E}$, Tomasz Roman Zdrojewski ${ }^{7, B, E}$, Wojciech Drygas ${ }^{2,3, B, E, F}$ \\ ${ }^{1}$ Department of Dietetics, Wroclaw Medical University, Poland \\ ${ }^{2}$ Department of Epidemiology, Cardiovascular Disease Prevention and Health Promotion, National Institute of Cardiology, Warszawa, Poland \\ ${ }^{3}$ Department of Social and Preventive Medicine, Medical University of Lodz, Poland \\ ${ }^{4}$ Department of Epidemiology and Population Studies, Institute of Public Health, Jagiellonian University Medical College, Kraków, Poland \\ ${ }^{5} 3^{\text {rd }}$ Department of Cardiology, Upper Silesian Center of Cardiology, Medical University of Silesia, Katowice, Poland \\ ${ }^{6}$ Department of Hypertension, Angiology and Internal Medicine, Poznan University of Medical Sciences, Poland \\ ${ }^{7}$ Department of Preventive Medicine and Education, Department of Hypertension and Diabetology, Medical University of Gdańsk, Poland \\ A - research concept and design; $\mathrm{B}$ - collection and/or assembly of data; $\mathrm{C}$ - data analysis and interpretation; \\ $D$ - writing the article; $E$ - critical revision of the article; $F$ - final approval of the article
}

Address for correspondence

Bożena Regulska-llow

E-mail: bozena.regulska-ilow@umed.wroc.pl

\section{Funding sources}

The WOBASZ II project was financed from the financial resources at the disposal of the Minister of Health within the framework of the health program entitled: National Program for the Equalization of Accessibility to Cardiovascular Disease Prevention and Treatment (POLKARD) for 2010-2012, within the goal for Analyses and Epidemiology - "Monitoring of the epidemiological situation in Poland in the field of cardiovascular diseases".

Conflict of interest

None declared

\section{Acknowledgements}

The authors wish to express special thanks to all of the research team and collaborating persons from the field centers in 16 voivodeships, and to all participants of the WOBASZI study. The authors are also especially grateful to Walerian Piotrowski, PhD, for the statistical analysis.

Received on September 14, 2017

Reviewed on February 7,2018

Accepted on August 9, 2018

Published online on April 5, 2019

DOI

10.17219/acem/94151

Copyright

Copyright by Author(s)

This is an article distributed under the terms of the Creative Commons Attribution Non-Commercial License (http://creativecommons.org/licenses/by-nc-nd/4.0/)

\section{Abstract}

Background. Cardiovascular disease (CVD) occurs more often among people with a low sociodemographic status, so it is worth knowing if any sociodemographic factor also has an impact on diet quality, defined by glycemic load (GL).

Objectives. Assessment of the relationship between the sociodemographic and lifestyle factors, health status self-assessment and dietary GL of the adult Polish population based on WOBASZ $\|$ study results.

Material and methods. The study included a representative group of the Polish population aged $\geq 20$ years (2,554 men and 3,136 women). A 24-hour dietary recall was collected to assess the dietary intake. The total $\mathrm{GL}$ was calculated by summing the $\mathrm{GL}$ values of the consumed food.

Results. The average $\mathrm{GL} / 1,000 \mathrm{kcal}$ was significantly higher in women's than in men's diets $(74.0 \pm 15.9 \mathrm{vs}$ $71.2 \pm 15.7$ ). Dietary GL/1,000 kcal increased with age (men: aged $<35-70.3$ and aged $\geq 65-73.9$, women: 73.5 and 76.5 , respectively). The lowest dietary GL/1,000 kcal was found among people living in large population centers. Dietary GL/1,000 kcal decreased with education level (men with primary, secondary and higher education: 73.4, 69.5 and 68.9, respectively, and women: 76.7,73.4 and 70.9, respectively). Dietary GL decreased as an income increased. The highest GL/1,000 kcal was observed in the diets of participants who performed less physical activity. The highest GL/1,000 kcal was observed in the participants who defined their health status as very poor/poor and the lowest among those who defined their health status as good/very good.

Conclusions. Nutritional education about the proper selection of products that are sources of carbohydrates in the diet should be addressed mainly to people with low sociodemographic status, such as: people in the older age group, living in small population centers, and with lower levels of education and lower income. It should also be directed to people with a lower level of physical activity. Greater awareness of the choices of carbohydrate products is recommended to improve diet quality in these groups of people.

Key words: carbohydrates, socio-demographic factors, glycemic load, WOBASZ II

\section{Cite as}

Różańska D, Waśkiewicz A, Regulska-llow B, et al. Relationship between the dietary glycemic load of the adult Polish population and socio-demographic and lifestyle factors - results of the WOBASZ II study. Adv Clin Exp Med. 2019;28(7):891-897. doi:10.17219/acem/94151 


\section{Introduction}

The European Society of Cardiology has emphasized that low socioeconomic status as well as other psychosocial factors (e.g., lack of social support, stress at work and in family life, depression, anxiety) increase the risk of developing cardiovascular disease (CVD) and contribute to a worse prognosis of CVD treatment. ${ }^{1}$ Kollia et al., based on a 10-year follow-up observation, proved that there is a consistent inverse relation between socioeconomic status and the incidence of CVD. ${ }^{2}$ In a study conducted by Kozakiewicz et al. in a random Polish population, increase in socioeconomic status was related to a decreased proportion of high CVD risk subjects in the overall study population and in participants aged $30-39$ years. ${ }^{3}$

Taking into account the fact that an unhealthy diet is also one of the risk factors for the development of CVD, it is worth knowing what sociodemographic factors have an impact on diet quality. Kwaśniewska et al., based on results obtained in the Multi-centre National Population Health Examination Survey in Poland (Project WOBASZ), observed that sociodemographic factors associated with fruit and vegetable consumption included: gender, age, place of residence, and health status self-assessment. ${ }^{4}$ Other authors showed that factors such as gender, age and level of education had a significant impact on the nutritional value of the diets of people residing in Swiętokrzyskie voivodeship. ${ }^{5}$

One of many values that can be used to describe diet quality is glycemic load (GL). It is calculated based on the glycemic index (GI) of food and the available carbohydrate content in the portion of the consumed food. Glycemic load provides an indication of glucose available for energy or storage following a carbohydrate-containing meal. It classifies food as having low $(\leq 10)$, medium $(>10$ $-<20)$ or high GL $(\geq 20) .{ }^{6}$ The results of many studies have shown that high dietary GL plays an important role in increasing the risk of CVD development. ${ }^{7,8}$

The mechanism of impact of high dietary GL on the human body can be diverse and can lead to several disorders which have been observed by, among others, Murakami et al. ${ }^{9}$ Their cross-sectional study conducted among 1,354 Japanese women aged 20-78 years showed that dietary GL was independently negatively correlated with high-density lipoprotein (HDL)-cholesterol, and positively correlated with fasting triacylglycerol and glucose level in blood. ${ }^{9}$ Other authors have observed that the intake of high GI/ GL foods may increase the risk of type 2 diabetes and lead to oxidative stress. ${ }^{10,11}$

Taking into account the arguments that dietary GL may be related to the risk of CVD development and that CVD occurs more often among people with lower sociodemographic status, it seems important to known which sociodemographic factors also have an influence on dietary GL. This is also relevant in view of the fact that there are no Polish studies concerning this topic.
The aim of the study was to assess the relationship between the sociodemographic and lifestyle factors, health status self-assessment and dietary GL in adult Polish population based on the WOBASZ II study results.

\section{Material and methods}

The study group consisted of a representative group of the Polish adult population aged $\geq 20$ years who participated in the project WOBASZ II conducted in the years 2013-2014. The assumption and methods of WOBASZ II, including the method of sample drawing, have been previously described by Drygas et al. ${ }^{12}$

This study was conducted among 5,690 participants (2,554 men and 3,136 women), who completed the 24-hour dietary recalls, based on which the dietary GL was computed. Moreover, the study participants were asked if they were on a diet (none, reducing diet, low fat/low cholesterol/ antidiabetic, other, e.g., anti-allergic) during the study.

The sociodemographic factors analyzed in this study included: age (which was categorized as: $<35$ years old, $35-49$ years old, 50-64 years old, $\geq 65$ years old), size of the population center (small, medium, large) inhabited, level of education (primary, secondary, higher), net monthly income per member of family $(<1,000$ PLN, 1,000-2,000 PLN, 2,000-3,000 PLN, >3,000 PLN), marital status (married, others: single, widow/widower, divorced, separated), smoking status (current smoker, former smoker, never-smoker), and level of physical activity during leisure time (low, moderate, high). Physical activity was assessed at a low level when there was no physical activity such as jogging, cycling, swimming, or gardening for at least 30 min a day or only occasional activity (once a month, several times a month, several times a year); middle level - physical activity such as jogging, cycling, swimming, or gardening for at least $30 \mathrm{~min}$ a day, every second or third day or once a week; high level - physical activity as given above every day or almost every day. Moreover, the study participants were asked for their health status self-assessment (very good and good, moderate, poor and very poor).

The nutritional value of the daily food rations (DFRs) was assessed with the use of Food Composition Tables. ${ }^{13}$ The GL values were computed based on the digestible carbohydrate content in the portion of the individual foods and the GI values of these foods, using the following formula:

$$
\begin{gathered}
\mathrm{GL}=[\text { digestible carbohydrate content } \\
\text { in the portion of food }[\mathrm{g}] \times \mathrm{GI}] / 100 \text {. }
\end{gathered}
$$

The total GL of each diet was calculated by summing the GL values of the foods consumed. There is no Polish database with the GI values of foods, so they were taken from international tables wherein GI values were determined experimentally for different food products and dishes. ${ }^{14-16}$ However, the GL values for typical Polish dishes which do not exist in international tables were computed based on their 
Table 1. Comparison of the mean dietary glycemic load, energy and macronutrient intake between the men and women studied

\begin{tabular}{|c|c|c|c|c|c|}
\hline \multirow{2}{*}{ Dietary compound } & \multicolumn{2}{|c|}{ Men } & \multicolumn{2}{|c|}{ Women } & \multirow{2}{*}{$p$-value } \\
\hline & $\mathrm{X} \pm \mathrm{SD}$ & $95 \% \mathrm{Cl}$ & $\mathrm{X} \pm \mathrm{SD}$ & $95 \% \mathrm{Cl}$ & \\
\hline Glycemic load/day & $163.6 \pm 72.2$ & $160.8-166.4$ & $124.1 \pm 54.2$ & $122.2-126.0$ & $<0.0001$ \\
\hline Glycemic load/1,000 kcal & $71.2 \pm 15.7$ & $70.5-71.8$ & $74.0 \pm 15.9$ & $73.5-74.6$ & $<0.0001$ \\
\hline Energy [kcal/day] & $2,317 \pm 935$ & $2,281-2,354$ & $1,678 \pm 639$ & $1,656-1,701$ & $<0.0001$ \\
\hline Carbohydrates [g/day] & $287.5 \pm 119.1$ & $282.9-292.1$ & $224.5 \pm 90.6$ & $221.3-227.7$ & $<0.0001$ \\
\hline Carbohydrates [\% energy] & $47.1 \pm 9.2$ & $46.8-47.5$ & $49.8 \pm 9.4$ & $49.5-50.1$ & $<0.0001$ \\
\hline Saccharose [g/day] & $57.3 \pm 46.6$ & $55.5-59.1$ & $51.0 \pm 38.5$ & $49.6-52.3$ & $<0.0001$ \\
\hline Starch [g/day] & $169.4 \pm 73.6$ & $166.6-172.3$ & $119.0 \pm 52.5$ & $117.2-120.9$ & $<0.0001$ \\
\hline Dietary fiber [g/day] & $20.9 \pm 9.1$ & $20.6-21.3$ & $17.5 \pm 7.8$ & $17.3-17.8$ & $<0.0001$ \\
\hline Protein [g/day] & $86.0 \pm 36.9$ & $84.6-87.5$ & $61.4 \pm 24.5$ & $60.6-62.3$ & $<0.0001$ \\
\hline Protein [\% energy] & $15.4 \pm 3.8$ & $15.2-15.5$ & $15.1 \pm 4.0$ & $14.9-15.2$ & $<0.0001$ \\
\hline Fats [g/day] & $97.0 \pm 49.3$ & $95.1-98.9$ & $66.2 \pm 32.3$ & $65.1-67.4$ & $<0.0001$ \\
\hline Fats [\% energy] & $37.5 \pm 8.4$ & $37.2-37.8$ & $35.1 \pm 8.5$ & $34.8-35.4$ & $<0.0001$ \\
\hline
\end{tabular}

$\mathrm{X} \pm \mathrm{SD}$ - average \pm standard deviation; $95 \% \mathrm{Cl}-95 \%$ confidence interval

recipes described in the Food Composition Tables. ${ }^{13}$ In order to assess the sources of GL of all foods and dishes, taking into account their nutritional value, they were classified into the following groups: dairy, refined and unrefined grains, sweets, vegetables, fruits, dried fruits, nuts and cocoa, potatoes and potato products, soups, juices, sweetened beverages, mixed dishes, alcoholic beverages, and others. Dietary GL strongly depends on energy intake and the amount of carbohydrates in the diet, ${ }^{17}$ therefore, for the analysis of values of dietary GL in this study, they were calculated for energy intake (GL/1,000 kcal), as it was done by other authors. ${ }^{9}$

\section{Statistical analysis}

The obtained results were summarized by average $(\mathrm{X})$ and standard deviation (SD). Dietary GL was adjusted for energy intake (GL/1,000 kcal). The differences in the nutritional values of the diets between 2 groups were compared using Mann-Whitney U test. The differences in the GL values of the diets between more than 2 groups were compared with the Kruskal-Wallis test. The results obtained were considered to be statistically significant at $\mathrm{p}<0.05$. Statistical analysis was performed using SAS software v. 9.2 (SAS Institute, Cary, USA).

\section{Results}

Table 1 shows a comparison of GL, energy and macronutrient intake of diets between men and women. The average GL in men's diets was significantly higher than in women's diets (163.6 \pm 72.2 vs $124.1 \pm 54.2)$; however, GL/1,000 kcal was significantly higher in women's diets than in men's diets $(74.0 \pm 15.9$ vs $71.2 \pm 15.7)$. Energy intake as well as the intake of all macronutrients was significantly higher in the DFRs of men than of women. The percentage of energy from proteins and fats was significantly higher in the diets of men than in the diets of women, while the percentage of energy from carbohydrates was significantly lower for men's diets than for women's diets.

The contribution of food groups in the dietary GL of men and women participating in the study is summarized in Table 2. The main sources of GL in the DFRs of men as well as in the DFRs of women were refined grain products (44.0\% and $35.3 \%$, respectively) and sweets (20.2\% and $24.9 \%$, respectively).

Table 3 shows the relationship between dietary GL (GL/1,000 kcal) and sociodemographic factors

Table 2. The contribution of food groups in the glycemic load of the diets of men and women participating in the study

\begin{tabular}{|c|c|c|c|c|}
\hline \multirow{2}{*}{ Food group } & \multicolumn{2}{|c|}{ Men } & \multicolumn{2}{|c|}{ Women } \\
\hline & $\mathrm{GL}(\mathrm{X} \pm \mathrm{SD})$ & $\%$ & $\mathrm{GL}(\mathrm{X} \pm \mathrm{SD})$ & $\%$ \\
\hline Dairy & $1.7 \pm 3.2$ & 1.0 & $1.8 \pm 2.6$ & 1.4 \\
\hline Refined grains & $71.9 \pm 48.9$ & 44.0 & $43.9 \pm 32.8$ & 35.3 \\
\hline Unrefined grains & $11.1 \pm 22.9$ & 6.8 & $9.5 \pm 16.3$ & 7.7 \\
\hline Sweets & $33.1 \pm 34.7$ & 20.2 & $30.9 \pm 31.4$ & 24.9 \\
\hline Vegetables & $3.7 \pm 5.5$ & 2.3 & $3.5 \pm 4.8$ & 2.8 \\
\hline Fruits & $8.2 \pm 13.0$ & 5.0 & $9.5 \pm 12.1$ & 7.6 \\
\hline Dry fruits & $0.2 \pm 2.2$ & 0.1 & $0.3 \pm 3.0$ & 0.3 \\
\hline Nuts and cocoa & $0.2 \pm 1.6$ & 0.2 & $0.2 \pm 1.2$ & 0.1 \\
\hline $\begin{array}{l}\text { Potatoes and potato } \\
\text { products }\end{array}$ & $5.0 \pm 16.7$ & 3.0 & $3.6 \pm 11.7$ & 2.9 \\
\hline Soups & $6.7 \pm 11.1$ & 4.1 & $6.1 \pm 9.3$ & 4.9 \\
\hline Juices & $1.8 \pm 6.0$ & 1.1 & $1.7 \pm 5.2$ & 1.4 \\
\hline Sweetened beverages & $3.8 \pm 12.8$ & 2.3 & $1.9 \pm 7.2$ & 1.5 \\
\hline Mixed dishes & $8.9 \pm 21.5$ & 5.5 & $6.9 \pm 17.3$ & 5.6 \\
\hline Alcoholic beverages & $1.0 \pm 3.9$ & 0.6 & $0.1 \pm 0.9$ & 0.1 \\
\hline Other & $7.0 \pm 10.4$ & 4.3 & $5.0 \pm 9.0$ & 4.0 \\
\hline Total & $163.6 \pm 72.2$ & 100 & $124.1 \pm 54.2$ & 100 \\
\hline
\end{tabular}

$\mathrm{GL}$ - glycemic load; $\mathrm{X} \pm \mathrm{SD}$ - average \pm standard deviation. 
Table 3. Relationship between dietary glycemic load (GL/1,000 kcal) and sociodemographic factors in the study population by sex

\begin{tabular}{|c|c|c|c|c|c|c|c|}
\hline & \multirow{2}{*}{ Factor } & \multicolumn{2}{|c|}{ Men } & \multirow{2}{*}{$p$-value } & \multicolumn{2}{|c|}{ Women } & \multirow{2}{*}{ p-value } \\
\hline & & $\mathrm{X} \pm \mathrm{SD}$ & $95 \% \mathrm{Cl}$ & & $\mathrm{X} \pm \mathrm{SD}$ & $95 \% \mathrm{Cl}$ & \\
\hline \multirow{4}{*}{ Age } & $<35$ years old $\left(n=602^{M} / 662^{W}\right)$ & $70.3 \pm 15.5$ & $69.0-71.5$ & \multirow{4}{*}{0.0016} & $73.5 \pm 15.7$ & $72.3-74.7$ & \multirow{4}{*}{$<0.0001$} \\
\hline & $35-49$ years old $\left(n=692^{M} / 825^{W}\right)$ & $70.6 \pm 15.7$ & $69.5-71.8$ & & $73.4 \pm 16.5$ & $72.3-74.5$ & \\
\hline & $50-64$ years old $\left(n=792^{M} / 1,011^{w}\right)$ & $70.6 \pm 15.7$ & $69.5-71.7$ & & $73.3 \pm 15.3$ & $72.3-74.2$ & \\
\hline & $\geq 65$ years old $\left(n=468^{M} / 637^{W}\right)$ & $73.9 \pm 15.6$ & $72.5-75.3$ & & $76.5 \pm 16.1$ & $75.3-77.8$ & \\
\hline \multirow{3}{*}{$\begin{array}{l}\text { Size of the inhabited } \\
\text { population center }\end{array}$} & small $\left(n=864^{m} / 1,139^{w}\right)$ & $73.3 \pm 15.0$ & $72.3-74.3$ & \multirow{3}{*}{$<0.0001$} & $76.4 \pm 15.6$ & $75.5-77.3$ & \multirow{3}{*}{$<0.0001$} \\
\hline & medium $\left(n=784^{M} / 961^{w}\right)$ & $70.9 \pm 15.1$ & $69.8-71.9$ & & $74.0 \pm 15.9$ & $73.0-75.0$ & \\
\hline & large $\left(n=906^{M} / 1,036^{W}\right)$ & $69.3 \pm 16.6$ & $68.2-70.4$ & & $71.4 \pm 16.0$ & $70.4-72.4$ & \\
\hline \multirow{3}{*}{ Level of education } & primary $\left(\mathrm{n}=1,135^{\mathrm{M}} / 1,136^{\mathrm{W}}\right)$ & $73.4 \pm 15.6$ & $72.5-74.3$ & \multirow{3}{*}{$<0.0001$} & $76.7 \pm 16.0$ & $75.8-77.7$ & \multirow{3}{*}{$<0.0001$} \\
\hline & secondary $\left(n=938^{m} / 1,200^{w}\right)$ & $69.5 \pm 15.9$ & $68.5-70.6$ & & $73.4 \pm 15.5$ & $72.6-74.3$ & \\
\hline & higher $\left(n=478^{M} / 796^{W}\right)$ & $68.9 \pm 14.9$ & $67.5-70.2$ & & $70.9 \pm 15.9$ & $69.8-72.0$ & \\
\hline \multirow{3}{*}{$\begin{array}{l}\text { Net month income } \\
\text { per member of family }\end{array}$} & $1,000-2,000$ PLN $\left(n=861^{M} / 1,056^{W}\right)$ & $70.5 \pm 15.9$ & $69.4-71.6$ & \multirow{3}{*}{$<0.0001$} & $73.6 \pm 15.6$ & $72.7-74.6$ & \multirow{3}{*}{$<0.0001$} \\
\hline & $2,000-3,000$ PLN $\left(n=253^{M} / 233^{W}\right)$ & $68.3 \pm 15.4$ & $66.4-70.3$ & & $68.3 \pm 16.3$ & $66.1-70.4$ & \\
\hline & $>3,000$ PLN $\left(n=122^{M} / 72^{W}\right)$ & $66.0 \pm 17.8$ & $62.8-69.2$ & & $68.0 \pm 17.3$ & $63.9-72.1$ & \\
\hline \multirow{2}{*}{ Marital status } & married $\left(n=1,792^{M} / 2,003^{W}\right)$ & $71.0 \pm 15.9$ & $70.3-71.8$ & \multirow{2}{*}{0.5428} & $73.7 \pm 16.0$ & $73.0-74.4$ & \multirow{2}{*}{0.0744} \\
\hline & other $^{*}\left(\mathrm{n}=761^{\mathrm{M}} / 1,133^{\mathrm{W}}\right)$ & $71.4 \pm 15.3$ & $70.3-72.5$ & & $74.6 \pm 15.8$ & $73.7-75.5$ & \\
\hline
\end{tabular}

$\mathrm{X} \pm \mathrm{SD}$ - average \pm standard deviation; $95 \% \mathrm{Cl}-95 \%$ confidence interval; ${ }^{\mathrm{M}}$ - men; ${ }^{\mathrm{W}}$ - - women; ${ }^{*}$ - single, widow/widower, divorced, separated.

Table 4. Relationship between dietary glycemic load (GL/1,000 kcal) and sociodemographic factors in the overall study population

\begin{tabular}{|c|c|c|c|c|}
\hline \multirow{2}{*}{\multicolumn{2}{|c|}{ Factor }} & \multicolumn{2}{|c|}{ Overall } & \multirow{2}{*}{$p$-value } \\
\hline & & $\mathrm{X} \pm \mathrm{SD}$ & $95 \% \mathrm{Cl}$ & \\
\hline \multirow{4}{*}{ Age } & $<35$ years old $(n=1,264)$ & $72.0 \pm 15.7$ & $71.1-72.8$ & \multirow{4}{*}{$<0.0001$} \\
\hline & $35-49$ years old $(n=1,517)$ & $72.1 \pm 16.2$ & $71.3-73.0$ & \\
\hline & $50-64$ years old $(n=1,803)$ & $72.1 \pm 15.5$ & $71.4-72.8$ & \\
\hline & $\geq 65$ years old $(n=1,105)$ & $75.4 \pm 16.0$ & $74.5-76.4$ & \\
\hline \multirow{3}{*}{$\begin{array}{l}\text { Size of the inhabited } \\
\text { population center }\end{array}$} & small $(\mathrm{n}=2,003)$ & $75.1 \pm 15.4$ & $74.4-75.7$ & \multirow{3}{*}{$<0.0001$} \\
\hline & medium $(n=1,745)$ & $72.6 \pm 15.6$ & $71.9-73.3$ & \\
\hline & large $(n=1,942)$ & $70.4 \pm 16.3$ & $69.7-71.1$ & \\
\hline \multirow{3}{*}{ Level of education } & primary $(n=2,271)$ & $75.1 \pm 15.9$ & $74.4-75.7$ & \multirow{3}{*}{$<0.0001$} \\
\hline & secondary $(n=2,138)$ & $71.7 \pm 15.8$ & $71.1-72.4$ & \\
\hline & higher $(n=1,274)$ & $70.1 \pm 15.5$ & $69.3-71.0$ & \\
\hline \multirow{4}{*}{$\begin{array}{l}\text { Net month income per } \\
\text { member of family }\end{array}$} & $<1,000$ PLN $(n=2,182)$ & $74.8 \pm 15.3$ & $74.2-75.5$ & \multirow{4}{*}{$<0.0001$} \\
\hline & $1,000-2,000$ PLN $(n=1,917)$ & $72.2 \pm 15.8$ & $71.5-72.9$ & \\
\hline & $2,000-3,000$ PLN $(n=486)$ & $68.3 \pm 15.8$ & $66.9-69.7$ & \\
\hline & $>3,000$ PLN $(n=194)$ & $66.7 \pm 17.6$ & $64.3-69.2$ & \\
\hline \multirow{2}{*}{ Marital status } & married $(n=3,795)$ & $72.4 \pm 16.0$ & $71.9-72.9$ & \multirow{2}{*}{0.0299} \\
\hline & other $^{*}(n=1,894)$ & $73.3 \pm 15.7$ & $72.6-74.0$ & \\
\hline
\end{tabular}

$X \pm S D$ - average \pm standard deviation; $95 \% \mathrm{Cl}$ - 95\% confidence interval; * - single, widow/widower, divorced, separated

in the study population by sex. Dietary GL/1,000 kcal increased significantly with the age of participants: among men aged $<35$ years, it was on average $70.3 \pm 15.5$ and among men aged $\geq 65$ years it was $73.9 \pm 15.6$, while among women it was on average $73.5 \pm 15.7$ and $76.5 \pm 16.1$, respectively. Significant differences in dietary $\mathrm{GL} / 1,000 \mathrm{kcal}$ were also observed depending on the size of the population center inhabited - the lowest was found in the DFRs of participants living in large population centers. The level of education also determined the GL value of the diets significantly: dietary GL/1,000 kcal of the diets decreased with increasing level of education, both in men and women. Moreover, dietary GL/1,000 kcal decreased significantly as the income increased. Marital 
Table 5. Relationship between dietary glycemic load (GL/1,000 kcal) and selected lifestyle factors in the study population by sex

\begin{tabular}{|c|c|c|c|c|c|}
\hline \multirow{2}{*}{\multicolumn{2}{|c|}{ Lifestyle determinant }} & Men & \multirow{2}{*}{ p-value } & Women & \multirow{2}{*}{ p-value } \\
\hline & & $\mathrm{X} \pm \mathrm{SD}$ & & $\mathrm{X} \pm \mathrm{SD}$ & \\
\hline \multirow{3}{*}{$\begin{array}{l}\text { Level of physical } \\
\text { activity }\end{array}$} & $\operatorname{low}\left(n=1,203^{M} / 1,402^{W}\right)$ & $71.9 \pm 15.8$ & \multirow{3}{*}{0.0435} & $74.8 \pm 16.0$ & \multirow{3}{*}{0.0088} \\
\hline & moderate $\left(n=642^{M} / 831^{w}\right)$ & $70.3 \pm 14.7$ & & $72.8 \pm 15.8$ & \\
\hline & high $\left(n=700^{M} / 892^{W}\right)$ & $70.7 \pm 16.4$ & & $73.8 \pm 16.0$ & \\
\hline \multirow{3}{*}{ Smoking status } & current smoker $\left(n=738^{M} / 585^{\mathrm{W}}\right)$ & $72.3 \pm 16.0$ & \multirow{3}{*}{0.0525} & $74.8 \pm 16.2$ & \multirow{3}{*}{$<0.0001$} \\
\hline & former smoker $\left(\mathrm{n}=857 \mathrm{M} / 590^{\mathrm{W}}\right)$ & $71.2 \pm 15.8$ & & $71.2 \pm 15.9$ & \\
\hline & never smoker $\left(n=954^{M} / 1,960^{w}\right)$ & $70.4 \pm 15.3$ & & $74.6 \pm 15.8$ & \\
\hline
\end{tabular}

$\mathrm{X} \pm \mathrm{SD}$ - average \pm standard deviation; ${ }^{\mathrm{M}}-\mathrm{men}^{\mathrm{W}}$ - women.

Table 6. Comparison of dietary glycemic load (GL/1,000 kcal) in the study population depending on the health status self-assessment

\begin{tabular}{|c|c|c|c|c|}
\hline \multirow{2}{*}{ Health status self-assessment } & Men & \multirow{2}{*}{$p$-value } & Women & \multirow{2}{*}{ p-value } \\
\hline & $\mathrm{X} \pm \mathrm{SD}$ & & $\mathrm{X} \pm \mathrm{SD}$ & \\
\hline Very good and good $\left(n=1,733^{M} / 2,019^{W}\right)$ & $70.8 \pm 15.8$ & \multirow{3}{*}{0.0426} & $73.4 \pm 15.8$ & \multirow{3}{*}{0.0191} \\
\hline Moderate $\left(n=662^{M} / 916^{W}\right)$ & $71.6 \pm 14.9$ & & $75.2 \pm 16.3$ & \\
\hline Poor and very poor $\left(n=101^{M} / 148^{W}\right)$ & $74.7 \pm 17.6$ & & $75.3 \pm 15.1$ & \\
\hline
\end{tabular}

$\mathrm{X} \pm \mathrm{SD}$ - average \pm standard deviation; ${ }^{\mathrm{M}}-$ men; ${ }^{\mathrm{W}}-$ women.

Table 7. Comparison of dietary glycemic load (GL/1,000 kcal) in the study population depending on the type of declared diet

\begin{tabular}{|c|c|c|c|c|}
\hline \multirow{2}{*}{ Type of diet } & Men & \multirow{2}{*}{$\mathrm{p}$-value } & Women & \multirow{2}{*}{$\mathrm{p}$-value } \\
\hline & $\mathrm{X} \pm \mathrm{SD}$ & & $\mathrm{X} \pm \mathrm{SD}$ & \\
\hline None $\left(n=2,311^{M} / 2,779^{W}\right)$ & $71.4 \pm 15.4$ & \multirow{4}{*}{0.0739} & $74.2 \pm 15.6$ & \multirow{4}{*}{0.0509} \\
\hline Reducing diet $\left(n=22^{M} / 41^{w}\right)$ & $69.5 \pm 19.5$ & & $65.6 \pm 23.9$ & \\
\hline Low-fat/low-cholesterol/antidiabetic $\left(n=182^{\mathrm{M}} / 251^{\mathrm{W}}\right)$ & $69.6 \pm 17.0$ & & $73.6 \pm 17.1$ & \\
\hline Other, e.g., anti-allergic $\left(n=39^{m} / 65^{w}\right)$ & $64.9 \pm 19.2$ & & $71.1 \pm 18.1$ & \\
\hline
\end{tabular}

$\mathrm{X} \pm \mathrm{SD}$ - average \pm standard deviation; ${ }^{\mathrm{M}}-$ men; $^{\mathrm{W}}$ - women.

status of the study group was not related to dietary GL/1,000 kcal. Table 4 shows the relationship between dietary GL/1,000 kcal and sociodemographic factors in the overall study population. The relationships observed in the overall study population were similar to those observed among men and women separately, aside from the marital status - dietary GL/1,000 kcal observed in the diets of married people was significantly lower than among others.

The relationship between GL/1,000 kcal and selected lifestyle factors in the study population by sex is presented in Table 5. The highest GL/1,000 kcal was observed in the diets of participants who declared low physical activity. Smoking status did not affect the GL/1,000 kcal in the diets of men. In contrast, among women, the lowest GL was observed in the DFRs of former smokers.

The lowest GL/1,000 kcal was observed in the diets of those participants who defined their health status as very good and good compared to those who defined their health status as moderate, poor or very poor (Table 6). The dietary GL/1,000 kcal was not significantly determined by the type of diet declared by the respondents (Table 7).

\section{Discussion}

Dietary GL is a value resulting from the amount of carbohydrates in food and their GIs. The average GLs were different between men's and women's diets; however, in both groups the main source of GL included refined grains followed by sweets. Products in these groups have high GI and are rich in carbohydrates and therefore their consumption has a dominant influence on the total GL. The contribution of other food groups in dietary GL was below $10 \%$. The contribution of all grain products in total GL in the women's diets was $43 \%$, which was similar to the results obtained among women participating in the Australian Longitudinal Assessment of Ageing in Women, where the contribution of grain products in total GL was $40.9 \% .{ }^{18}$ However, in the diets of Australian women sweets were the source of $13.6 \%$ of GL while in the Polish women it was $24.9 \%$. It is also worth noting that in the DFRs of Australian women, fruits have almost 2-fold higher contribution to total GL compared to the DFRs of Polish women (14.2\% vs $7.6 \%$ ), while the contribution of vegetables was similar and amounted to $2.8 \%$. Taking into account 
the abovementioned differences, it can be assumed that the diets of women from the study population contained less fruits and more sweets than the diets of Australian women. ${ }^{18}$ The contribution of all grain products in total GL in the studied men's diet was $50.8 \%$, which was more than in the diets of Swedish men, where these products were the source of $36.7 \%$ of total GL. ${ }^{19}$ On the other hand, in the DFRs of the men studied, potatoes and potato products were the source of $3.0 \%$ of GL, while in the DFRs of Swedish men it was $12.7 \%$. However, a similar contribution of sweets ( $20.2 \%$ vs $22.6 \%$, respectively) and fruits (5.0\% vs $5.2 \%)$ in the diets of men from both groups was observed. ${ }^{19}$ The GL in the diets of Polish women was higher compared to Australians (124.1 vs 115.0 per $1,000 \mathrm{kcal}$ ), while the GL in the diets of Polish men was lower compared to Swedes (163.6 vs 211.0 per $1,000 \mathrm{kcal}) .^{18,19}$ Differences between food contribution in dietary GL among the abovementioned countries show that various dietary habits have an influence on dietary GL.

As was mentioned before, dietary GL is associated with energy intake. To minimize the influence of very low and very high energy diets on the dietary GL in this study, dietary GL was calculated per 1,000 kcal. Such calculation made it possible to compare the presented results with other authors, who also adjusted their results to the energy value of the diet. ${ }^{10,20-24}$

In this study, the relationships between sociodemographic factors such as age, size of the population center inhabited, level of education and net monthly income per member of family, and the value of dietary GL/1,000 kcal were found. We have observed that dietary GL/1,000 kcal increased with age, which was also observed by other authors. ${ }^{10,20,21}$ However, in the Krishnan et al. study conducted in US black women, energy-adjusted GL was negatively associated with age. ${ }^{22}$ We have also observed that dietary GL/1,000 kcal was lower among people residing in large population centers compared to those from small population centers. The same significant relationship was found for total GL. There are few studies which have examined such relationships; however, Hlaing et al. found a significantly lower total GL among people from suburban in comparison to urban areas in Myanmar. ${ }^{23}$

Another factor that was related to dietary GL was the level of education. Higher level of education among the Polish population was related to lower GL/1,000 kcal, and also to lower total GL. Villegas et al. observed a similar relationship in middle-aged Chinese women. Among people from the $5^{\text {th }}$ quintile of energy-adjusted GL, there were significantly fewer people with college education (6.3\%) and significantly more people with no education (36.5\%) in comparison to the $1^{\text {st }}$ quintile $(19.8 \%$ and $7.4 \%$, respectively). ${ }^{10}$ Similar results were obtained by Sahyoun et al. in the Health, Aging and Body Composition Study conducted among 70-79-year-old people from Pittsburgh and Memphis, USA. ${ }^{24}$ Levitan et al. also found that among middle-aged and older Swedish men from the $4^{\text {th }}$ quartile of energy-adjusted GL, there were significantly fewer people with university education (13.5\%) and significantly more people with less than high school education (73.8\%) compared to the $1^{\text {st }}$ quartile ( $20.9 \%$ and $63.1 \%$, respectively). ${ }^{21}$

In the present study, an inverse relationship between the net monthly income per family member and dietary GL/1,000 kcal was observed. Villegas et al. also found that higher income was more often found among middle-aged Chinese women whose diets had low GL (energy-adjusted). ${ }^{10}$ These 3 factors (place of residence, level of education and income) may be connected to each other because the level of education of people living in rural areas is often lower and people with lower level of education often have lower income. Such relationships were observed in the WOBASZ study conducted between 2003 and $2005 .{ }^{25}$ In small population centers, $75.4 \%$ of men had elementary education, $19.9 \%$ had secondary education and $4.7 \%$ had university education, while in large population centers these percentages were $47.7 \%, 37.8 \%$ and $14.5 \%$, respectively. Moreover, in small population centers, $83.0 \%$ of men reported that their net monthly income per member of family was $<700$ PLN, $15.4 \%$ reported 700-1500 PLN and $1.6 \%$ reported more than 1500 PLN. Similar observations were noted in the group of women. ${ }^{25}$

What is interesting is that marital status in the study population did not have any impact on dietary GL/1,000 kcal. Levitan et al. showed that marital status was related to dietary GL in the group of Swedish men. ${ }^{21}$ In the $4^{\text {th }}$ quartile of energy-adjusted GL, compared to the others, the percentage of married men was the lowest and the percentage of single men was the highest. However, the highest percentage of divorced men was observed in the $1^{\text {st }}$ quartile of dietary GL. On the other hand, there was a similar percentage of widowed men in every quartile of dietary GL. ${ }^{21}$

Besides the abovementioned sociodemographic factors, we also included 2 lifestyle determinants in our analyses: level of physical activity and smoking status. The $1^{\text {st }}$ one was to a large extent related to the GL/1,000 kcal of the diets in the study population. Sahyoun et al. in the Health, Aging and Body Composition Study did not observe significant differences in physical activity between participants from different quintiles of energy-adjusted dietary GL. ${ }^{24}$ However, in postmenopausal Spanish women from the PREDIMED study, the highest level of physical activity (185.0 METs-h/w) was noted among the participants from the $1^{\text {st }}$ tertile of energy-adjusted GL compared to the $2^{\text {nd }}$ (162.8 METs-h/w) and $3^{\text {rd }}(171.8 \mathrm{METs}-\mathrm{h} / \mathrm{w})$ tertiles. $^{20}$ On the other hand, Krishnan et al. found the highest percentage of US black women with vigorous physical activity in the $5^{\text {th }}$ quintile of energy-adjusted GL in comparison to other quintiles. ${ }^{22}$ In middle-aged and older Swedish men, the highest level of physical activity $(58.6 \mathrm{~min} /$ day) was observed in participants from the $4^{\text {th }}$ quartile of energy-adjusted GL in comparison to other quartiles $\left(1^{\text {st }}-53.9 \mathrm{~min} /\right.$ day, $2^{\text {nd }}-56.7 \mathrm{~min} /$ day, $3^{\text {rd }}-57.6 \mathrm{~min} /$ day $) .{ }^{21}$ 
Smoking status was associated with dietary GL/1,000 kcal only in the diets of women - the lowest GL was found in the DFRs of former smokers. However, the results of other studies differ between each other. Krishnan et al. observed the highest rate of cigarette use in US black women from the $1^{\text {st }}$ quintile of energy-adjusted GL compared to the other groups. ${ }^{22}$ Among Swedish men, the lowest percentage of never-smokers $(31.4 \%)$ was found in the $1^{\text {st }}$ quartile of energy-adjusted GL compared to the $2^{\text {nd }}, 3^{\text {rd }}$ and $4^{\text {th }}$ quartile $(37.7 \%, 40.1 \%$ and $40 \%$, respectively). Taking into account former and current smokers, an inverse relationship was found..$^{21}$ On the other hand, Castro-Quezada et al. did not observe significant differences in the percentage of current smokers, former smokers and never-smokers among Spanish women between tertiles of energy-adjusted dietary GL. ${ }^{20}$

Based on the study results, it was also shown that the health status self-assessment was related to the value of dietary GL/1,000 kcal, in contrast to the type of declared diet. People who assessed their health status as good and very good had significantly lower dietary GL than other people. Such relationships have not been analyzed by other authors. Probably the health status self-assessed as poor or very poor may be caused, among others, by unhealthy lifestyle, including unhealthy diet. However, such analyses were not assessed in this study.

\section{Conclusions}

Nutritional education about the proper selection of products that are sources of carbohydrates in the diet should be addressed mainly to people with low sociodemographic status, such as people in the older age group, living in small population centers, with lower levels of education and lower income, and also to people with lower levels of physical activity. Greater awareness of the choices of carbohydrate products is recommended to improve the quality of diet in these groups of people.

\section{References}

1. Piepoli MF, Hoes AW, Agewall S, et al; Authors/Task Force Members. 2016 European Guidelines on cardiovascular disease prevention in clinical practice. Eur Heart J. 2016;37(29):2315-2381.

2. Kollia N, Panagiotakos DB, Georgousopoulou E, et al. Exploring the association between low socioeconomic status and cardiovascular disease risk in healthy Greeks, in the years of financial crisis (2002-2012): The ATTICA study. Int J Cardiol. 2016;223:758-763.

3. Kozakiewicz K, Podolecka E, Kwaśniewska M, Drygas W, Pająk A, Tendera M. Association between socioeconomic status and cardiovascular risk. Kardiol Pol. 2016;74(2):179-184.

4. Kwaśniewska M, Bielecki W, Kaczmarczyk-Chałas K, Pikala M, Drygas W. Ocena rozpowszechnienia zdrowego stylu życia wśród dorosłych mieszkańców województwa łódzkiego i lubelskiego - Projekt WOBASZ. Prz Lek. 2007;64(2):61-64.
5. Ilow R, Regulska-llow B, Różańska D, et al. Assessment of dietary intake in a sample of Polish population - baseline assessment from the prospective cohort "PONS" study. Ann Agric Environ Med. 2011; 18(2):229-234.

6. Venn BJ, Green TJ. Glycemic index and glycemic load: Measurement issues and their effect on diet-disease relationships. Eur J Clin Nutr. 2007;61(Suppl 1):S122-S131.

7. Beulens JWJ, de Bruijne LM, Stolk RP, et al. High dietary glycemic load and glycemic index increase risk of cardiovascular disease among middle-aged women. J Am Coll Cardiol. 2007;50(1):14-21.

8. Burger KNJ, Beulens JWJ, Boer JMA, Spijkerman AMW, van der ADL. Dietary glycemic load and glycemic index and risk of coronary heart disease and stroke in Dutch men and women: The EPIC-MORGEN Study. PLoS One. 2011;6(10):e25955. doi:10.1371/journal.pone.0025955

9. Murakami K, Sasaki S, Takahashi Y, et al. Dietary glycemic index and load in relation to metabolic risk factors in Japanese female farmers with traditional dietary habits. Am J Clin Nutr. 2006;83(5):1161-1169.

10. Villegas R, Liu S, Gao YT, et al. Prospective study of dietary carbohydrates, glycemic index, glycemic load, and incidence of type 2 diabetes mellitus in middle-aged Chinese women. Arch Intern Med. 2007;167(21):2310-2316.

11. Hu Y, Block G, Norkus EP, Morrow JD, Dietrich M, Hudes M. Relations of glycemic index and glycemic load with plasma oxidative stress markers. Am J Clin Nutr. 2006;84(1):70-76.

12. Drygas W, Niklas AA, Piwońska A, et al. Multi-centre National Population Health Examination Survey (WOBASZ II study): Assumptions, methods, and implementation. Kardiol Pol. 2016;74(7):681-690.

13. Kunachowicz H, Przygoda B, Irena N, Iwanow K. Tabele składu i wartości odżywczej żywności. Warszawa, Poland: Wydawnictwo Lekarskie PZWL; 2005.

14. Foster-Powell K, Holt SH, Brand-Miller JC. International table of glycemic index and glycemic load values: 2002. Am J Clin Nutr. 2002;76(1): 5-56.

15. Atkinson FS, Foster-Powell K, Brand-Miller JC. International Tables of Glycemic Index and Glycemic Load Values: 2008. Diabetes Care. 2008;31(12):2281-2283.

16. National Cancer Institute. Tables of Gl; http://riskfactor.cancer.gov/ DHQ/database/\#gl (Accessed in September 2006).

17. Różańska D, Kawicka A, Konikowska K, et al. Assessment of glycemic load and intake of carbohydrates in the diets of Wroclaw Medical University students (Poland). Rocz Panstw Zakl Hig. 2016;67(3):301-308.

18. O'Sullivan TA, Bremner AP, Cedaro PC, O'Neill S, Lyons-Wall P. Glycaemic index and glycaemic load intake patterns in older Australian women. Nutr Diet. 2009;66(3):138-144.

19. Levitan EB, Westgren CW, Liu S, Wolk A. Reproducibility and validity of dietary glycemic index, dietary glycemic load, and total carbohydrate intake in 141 Swedish men. Am J Clin Nutr. 2007;85(2):548-553.

20. Castro-Quezada I, Sánchez-Villegas A, Martínez-González MÁ, et al; PREDIMED Study Investigators. Glycemic index, glycemic load and invasive breast cancer incidence in postmenopausal women: The PREDIMED study. Eur J Cancer Prev. 2016;25(6):524-532.

21. Levitan EB, Mittleman MA, Håkansson N, Wolk A. Dietary glycemic index, dietary glycemic load, and cardiovascular disease in middleaged and older Swedish men. Am J Clin Nutr. 2007;85(6):1521-1526.

22. Krishnan S, Rosenberg L, Singer M, et al. Glycemic index, glycemic load, and cereal fiber intake and risk of type 2 diabetes in US black women. Arch Intern Med. 2007;167(21):2304-2309.

23. Hlaing $\mathrm{HH}$, Liabsuetrakul T. Dietary intake, food pattern, and abnormal blood glucose status of middle-aged adults: A cross-sectional community-based study in Myanmar. Food Nutr Res. 2016,60(1): 28898. http://dx.doi.org/10.3402/fnr.v60.28898

24. Sahyoun NR, Anderson AL, Tylavsky FA, Lee JS, Sellmeyer DE, Harris TB; Health, Aging, and Body Composition Study. Dietary glycemic index and glycemic load and the risk of type 2 diabetes in older adults. Am J Clin Nutr. 2008;87(1):126-131.

25. Waśkiewicz A, Sygnowska E. Czy jakość diety dorosłych mieszkańców Polski zależna jest od miejsca zamieszkania? - Projekt WOBASZ. Probl Hig Epidemiol. 2009;90(2):206-211. 